\title{
INVESTIGATION OF MECHANICAL METHOD OF TRICHOGRAM DISPERSAL
}

\author{
Valentyna Krutyakova $^{1}$, Volodymyr Bulgakov ${ }^{2}$, Volodymyr Belchenko ${ }^{1}$, Adolfs Rucins ${ }^{3}$ \\ ${ }^{1}$ Engineering and Technology Institute "Biotechnica", Ukraine; \\ ${ }^{2}$ National University of Life and Environmental Sciences of Ukraine, Ukraine; \\ ${ }^{3}$ Latvia University of Life Sciences and Technologies, Latvia \\ semjons@apollo.lv
}

\begin{abstract}
The biological methods of combat with pests and plant diseases (for example, the use of trichograms) have great prospects. An important step in successful application of the industrial technologies of biological plant protection, based on the use of trichograms, is their final operation, that is, the dispersal of the trichograms on the field. The simplest and most reliable method is the mechanical method of acceleration of a trichogram, with the help of which uniform mechanical propagation of capsules over the field is carried out. One of the variants of mechanical dispersal of encapsulated trichograms is spreading by means of pneumatic devices. The purpose of the work is to study the operation of a pneumatic installation for the dispersal of trichograms and determination of its rational parameters. A computational mathematical model has been constructed, describing the dispersal of trichograms by means of a pneumatic installation. Constructive and kinematic parameters of the installation for scattering (dispersal) the capsules with trichograms have been determined, which ensures high uniformity of dispersal of the trichograms across the surface of the field. We have created an installation for dispersal of encapsulated trichograms.
\end{abstract}

Keywords: trichogram (Trichogramma evanescens L.), capsule, parameters, installation.

\section{Introduction}

The use of pesticides in agriculture has adverse environmental consequences [1]. Contemporary methods of improving the efficiency of sprayers, application of new chemicals, etc. still retain great environmental risks and are unacceptable in biological agriculture [2].

The biological methods of combat with pests and plant diseases (for example, the use of trichograms) have great prospects [3-6]. Trichogram (Trichogramma evanescens L.) is a family of parasitic insects that feed on the entrails of eggs laid by various pests of gardens and orchards. Eggeaters are bred artificially (in laboratories and biofactories), and for their breeding grain moth eggs are generally used, which are cultivated on barley grain, and then dispersed into natural field conditions. In Ukraine, in the overwhelming majority of cases, the trichogram is efficiently used to combat the stem butterfly on the maize plantations [7]. Ninety-nine percent of all similar entomophages are the egg-eaters of stem butterflies.

An important step in successful application of the industrial technologies of biological plant protection, based on the use of trichograms, is their final operation, that is, the dispersal of the trichograms on the field. Attempts to carry out qualitative dispersal of the trichograms by means of various aircraft do not find a successful solution. One of the simplest and most reliable ways is the mechanical method of the trichogram dispersal, by which uniform mechanical spreading of capsules across the field is carried out [8;9]. One of the variants of mechanical dispersal of encapsulated trichograms is spreading by means of pneumatic devices.

When creating technical means for the dispersal, it is necessary to take into account that the working tools of the distributor ensure and do not reduce the viability and the pre-set parameters of the physical and mechanical properties of the biomaterial. In addition, during the trichogram dispersal it is necessary to ensure uniform distribution of the biomaterial on the treated areas of the field. Due to the relative novelty of massive use of this biological method of the pest control, the research of the mechanical method of the trichogram dispersal is reflected in literature scarcely, and it is not related to specific parameters of the technical means for its implementation [10-12].

The purpose of the work is to study the operation of a pneumatic installation for the dispersal of trichograms and determination of its rational parameters.

\section{Materials and methods}

We have created an installation for the dispersal of encapsulated trichograms (Fig. 1). The installation consists of a frame, on which there are placed five pneumatic guns 1 , an air compressor 2 , 
a receiver 3 , a distribution manifold 4 , and solenoid valves 5 . All the five pneumatic guns 1 are interconnected by pneumatic hoses 6 . There is also an automatic control panel 7 mounted on the frame. Each pneumatic gun 1 is a metal case, in which a capsule ejection actuator is located. A metal pipe is attached to this case, which is used as a barrel. The barrel should be inclined to the horizon. On top of the body of each gun 1 there is a hopper 8 for the trichogram capsules. The design of each gun 1 provides for a possibility that, after one shot is made, only one capsule with a trichogram will fall from the hopper into the body of the gun. Next, after a certain interval of time, the next shot follows. Besides, when fired, the pressure of air pressing upon the capsule with the trichogram abruptly causes it to fly out of the barrel of the gun 1 into the environment at a corresponding initial speed. The automatic control panel 7 , which is connected to the solenoid valves 5 of each gun 1 , actually controls the frequency of their shots.

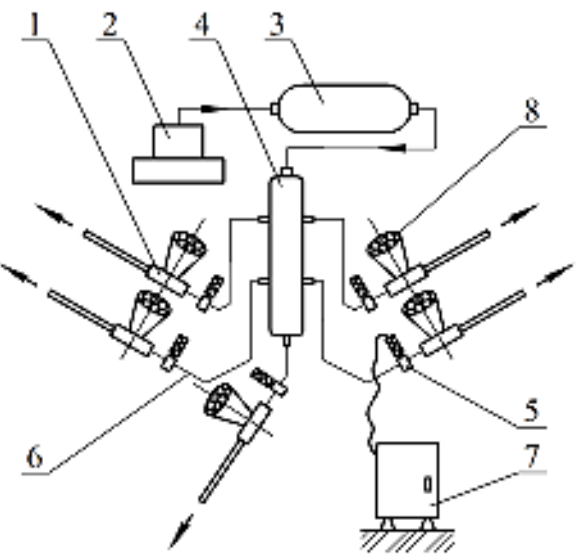

Fig. 1. Installation for dispersal of encapsulated trichograms

The distributor of the trichogram dispersal gradually moves across the field by means of a motor cart (a two-wheeled tractor), or a tractor trailer. In this case, the operation of the air compressor 2 must be provided from the power take-off shaft of this vehicle.

An important aspect in the operation of this distributor is to define the distance and height of the flight of the capsule with the trichogram, which will determine the dispersion zone, the dispersal uniformity on the field and will, in fact, ensure the performance of the spreader. When using two guns at once on both sides of this distributor, correction of two paths of the movement of their capsules is necessary, which will ensure different points of landing of the capsules and provide the general required uniformity of the dispersal of the trichograms across the field.

For theoretical understanding of the distribution process of a capsule (a conditional material point), we construct an equivalent pattern of the movement in a longitudinal-vertical plane (Fig. 2). We assume that the end of the barrel of the gun, located at point $O$, conditionally is coinciding with the horizontal surface of the field. In the future the height of the cart, on which the gun is placed, and the height of the end of its vertically located barrel can be easily taken into account in further numerical calculations. Further, considering the movement of a body (a material point), thrown at an angle to the horizon $\alpha$ at an initial speed $\bar{V}_{0}$ (without considering air resistance), will ultimately have the following well-known dependencies for determination of the maximum distance and altitude of the flight $[13 ; 14]$. Equations of the movement of a body thrown at an angle to the horizon have the form:

$$
\left.\begin{array}{l}
x=\left(V_{0} \cos \alpha\right) \cdot t, \\
y=\left(V_{0} \sin \alpha\right) \cdot t-\frac{g t^{2}}{2} .
\end{array}\right\}
$$

Depending on the inclination angle $\alpha$ of the barrel of the gun, the distance $L$ of the flight of the body, that is, the capsule with a trichogram, at a given initial velocity $V_{0}$ of the movement of the capsule, when firing, will be:

$$
L=x\left(t_{1}\right)=V_{0} \cos \alpha \cdot t_{1}=\frac{V_{0} \cos \alpha \cdot 2 V_{0} \sin \alpha}{g}=\frac{V_{0}^{2}}{g} \sin 2 \alpha
$$


The maximum distance $L_{\max }$ of the flight of the capsule with a trichogram will be possible, if the barrel of the gun is tilted at an angle $\alpha$, equal to $45^{\circ}$.

The maximum height of the flight of the capsule, depending on the inclination angle of the gun:

$$
H_{\text {max }}=\frac{V_{0}^{2} \cdot \sin ^{2} \alpha}{2 g} .
$$

In order to determine the path of the movement of the body, we exclude the parameter $t$ from the last equations of the movement (1). From the first equation of this system we define the time $t$. It will be equal to:

$$
t=\frac{x}{V_{0} \cos \alpha} .
$$

Next, we substitute expression (4) into the second equation of the system (1). We have:

$$
y=\frac{\left(V_{0} \sin \alpha\right) x}{V_{0} \cos \alpha}-\frac{g x^{2}}{2 V_{0}^{2} \cos ^{2} \alpha} .
$$

If we consider that:

$$
\frac{1}{\cos ^{2} \alpha}=1+\tan ^{2} \alpha,
$$

then expression (5) can be represented as follows:

$$
y=x \cdot \tan \alpha-\frac{g\left(1+\tan ^{2} \alpha\right)}{2 V_{0}^{2}} \cdot x^{2} .
$$

We introduce the following notation:

$$
\begin{gathered}
A=\tan \alpha, \\
B=\frac{g\left(1+\tan ^{2} \alpha\right)}{2 V_{0}^{2}},
\end{gathered}
$$

therefore, expression (7) with regard to (21) and (22) will have the following form:

$$
y=A x-B x^{2} .
$$

The resulting expression (10) determines a path of the movement corresponding to a parabola. There may also be set a task to determine the required angle $\alpha$, at which the path passes through the prep-set point in space. To determine the angle, at which it is necessary to shoot the capsule with a trichogram so that it passes through a pre-set point $K\left(x_{1}, y_{1}\right)$ in expression (7), we substitute the coordinates of point $K$, that is $x_{1}, y_{1}$. We have:

$$
y_{1}=x_{1} \cdot \tan \alpha-\frac{g\left(1+\tan ^{2} \alpha\right)}{2 V_{0}^{2}} \cdot x_{1}^{2} .
$$

Expression (11) is a quadratic equation for the unknown $\tan \alpha$, which will have two solutions $\tan \alpha_{1}$ and $\tan \alpha_{2}$ (and corners $\alpha_{1}$ and $\alpha_{2}$, respectively). We rewrite expression (11) as follows:

$$
\frac{g\left(1+\tan ^{2} \alpha\right)}{2 V_{0}^{2}} x_{1}^{2}-x_{1} \tan \alpha+y_{1}=0,
$$

or

$$
\frac{g \cdot x_{1}^{2}}{2 V_{0}^{2}} a \cdot \tan ^{2} \alpha-x_{1} \tan \alpha+\left(y_{1}+\frac{g \cdot x_{1}^{2}}{2 V_{0}^{2}}\right)=0 .
$$

Let us solve the quadratic equation (13). We introduce the following notation: 


$$
\begin{gathered}
R=\frac{g \cdot x_{1}^{2}}{2 V_{0}^{2}}, \\
M=y_{1}+\frac{g \cdot x_{1}^{2}}{2 V_{0}^{2}} .
\end{gathered}
$$

Taking into account (14) and (15), the quadratic equation (13) will have the following form:

$$
R \cdot \tan ^{2} \alpha-x_{1} \cdot \tan \alpha+M=0 .
$$

Finally, we obtain the following solution of the quadratic equation (16):

$$
\tan \alpha=\frac{x_{1} \pm \sqrt{x_{1}^{2}-4 R M}}{2 R} .
$$

Accordingly, the two roots of equation (16) will have the following values:

$$
\begin{aligned}
& \tan \alpha_{1}=\frac{x_{1}+\sqrt{x_{1}^{2}-4 R M}}{2 R}, \\
& \tan \alpha_{2}=\frac{x_{1}-\sqrt{x_{1}^{2}-4 R M}}{2 R} .
\end{aligned}
$$

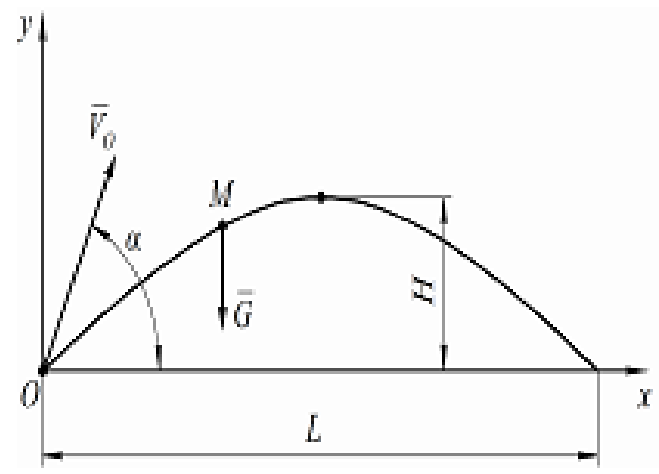

Fig. 2. Equivalent scheme of flight of capsule with trichogram, thrown at angle to horizon

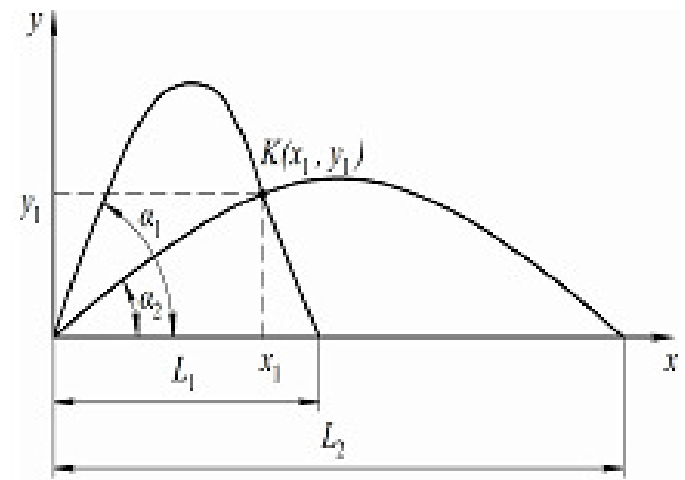

Fig. 3. Paths of movement of capsule with trichogram, thrown at angles $\alpha_{1}$ and $\alpha_{2}$ when passing through point $K$

\section{Results and discussion}

Experimental investigations have been carried out to determine the technical parameters of the experimental installation for mechanical dispersal of trichograms.

To determine the ballistic characteristics, capsules were fired, changing the following design parameters of the model: the lengths of the barrel $-2 \mathrm{~m}, 1.5 \mathrm{~m}, 1 \mathrm{~m}$ and $0.5 \mathrm{~m}$; the inclination angles of the barrel $-45,35,30$ and 25 degrees. In each shot there were recorded the distance of the capsule and its deviation from a pre-set direction. The results of these studies are presented in Table 1.

One can see from the results that, to make $20-22 \mathrm{~m}$ long shots, it is sufficient to supply an air pressure of $4 \mathrm{~atm}$ into the pneumatic gun with a $7 \mathrm{~mm}$ diameter of the central hole in the piston, and for a shot 10-12 $\mathrm{m}$ far, the air pressure should be 200-300 $\mathrm{kPa}$, and the diameter of the hole in the piston can be reduced to $5 \mathrm{~mm}$. Such installation parameters can significantly reduce the overall air consumption, i.e. they can make operation of the installation more economical and reliable.

To calculate the performance of the air compressor, the following input data were used (Table 3). Calculations, using the Saint Venant formula [13], showed that, for these conditions, the minimum required air consumption (and also the minimum efficiency of the air compressor) per 1 minute is $473 \mathrm{dm}^{3}$. 
Results of investigations to determine the ballistic characteristics of the installation

Table 1

\begin{tabular}{|c|c|c|}
\hline Length of the barrel, $\mathbf{~ m}$ & $\begin{array}{c}\text { Inclination angle of the } \\
\text { barrel, degree }\end{array}$ & $\begin{array}{c}\text { Average distance of the } \\
\text { flight of capsules, m }\end{array}$ \\
\hline 2.0 & 45 & 27 \\
\hline 2.0 & 35 & 26 \\
\hline 2.0 & 30 & 25 \\
\hline 2.0 & 25 & 25 \\
\hline 1.5 & 45 & 29 \\
\hline 1.5 & 35 & 28 \\
\hline 1.5 & 30 & 29 \\
\hline 1.5 & 25 & 25 \\
\hline 1.0 & 45 & 25 \\
\hline 1.0 & 35 & 24 \\
\hline 1.0 & 30 & 23 \\
\hline 1.0 & 25 & 22 \\
\hline 0.5 & 45 & 24 \\
\hline 0.5 & 35 & 24 \\
\hline 0.5 & 30 & 23 \\
\hline 0.5 & 25 & 21 \\
\hline
\end{tabular}

Table 2

Results of investigations to determine the design characteristics of the installation

\begin{tabular}{|c|c|c|}
\hline $\begin{array}{c}\text { Air pressure, bar } \\
(\mathbf{1} \text { bar }=\mathbf{1 0} \mathbf{~ P a})\end{array}$ & $\begin{array}{c}\text { Diameter of the piston } \\
\text { hole, } \mathbf{~ m m}\end{array}$ & $\begin{array}{c}\text { Average flight distance } \\
\text { of capsules, } \mathbf{~}\end{array}$ \\
\hline 6 & 6 & 30 \\
\hline 6 & 4 & 26 \\
\hline 6 & 3 & 14 \\
\hline 6 & 2 & 5 \\
\hline 4 & 6 & 25 \\
\hline 4 & 4 & 21 \\
\hline 4 & 3 & 10 \\
\hline 4 & 2 & 4 \\
\hline 3 & 6 & 20 \\
\hline 3 & 4 & 16 \\
\hline 3 & 3 & 7 \\
\hline 3 & 2 & 3 \\
\hline 2 & 6 & 15 \\
\hline 2 & 4 & 13 \\
\hline 2 & 3 & 5 \\
\hline 2 & 2 & 1 \\
\hline
\end{tabular}

At the first stage of testing, a barrel longer than $500 \mathrm{~mm}$ was found to have no significant effect on the flight distance of the capsules. For this reason, a barrel from 585 to $450 \mathrm{~mm}$ was used in the subsequent experiments. During the functional field tests of the experimental specimen of the installation the required length of the barrel of the pneumatic gun was determined, (Fig. 4). It was found that the reduction in the length of the barrel to $450 \mathrm{~mm}$ will increase the distance of the flight of the capsule; yet further reduction in the length of the barrel to $400 \mathrm{~mm}$ will decrease also the distance of the flight of the capsule.

The dependence of the distance of the flight of the capsule on the air pressure acting upon it was also determined. It was established experimentally that for a shot at a distance of 20-25 m, an air pressure of 4-5 bar is sufficient, and at $10 \mathrm{~m}$, air pressure of 2-3 bar is sufficient. For these conditions it is required to load 9000 pcs. capsules into the hopper at a time, for which a $4 \mathrm{dm}^{3}$ hopper is needed. 
Input data to calculate the performance of the air compressor

\begin{tabular}{|l|c|}
\hline \multicolumn{1}{|c|}{ Input data } & Value \\
\hline Working air pressure in the receiver, $\mathrm{kPa}$ & $\sim 639$ \\
\hline Length of the barrel, $\mathrm{mm}$ & 450 \\
\hline Internal diameter of the barrel, $\mathrm{mm}$ & 21 \\
\hline Diameter of the holes in the pistons, $\mathrm{mm}$ & $d_{3}=6, d_{2}=4, d_{1}=3, d_{0}=2$ \\
\hline Duration of the pause between the shots, $\mathrm{sec}^{-1}$ & 4 \\
\hline Duration of the valve opening, $\mathrm{sec}^{-1}$ & 0.5 \\
\hline Air temperature during the spraying process $\sim$ & $20^{\circ} \mathrm{C}\left(293^{\circ} \mathrm{K}\right)$ \\
\hline Atmospheric pressure $P_{0}, \mathrm{~Pa}$ & $10^{5}$ \\
\hline
\end{tabular}

Table 3

Data for calculation of the volume of the capsule hopper

\begin{tabular}{|l|c|}
\hline \multicolumn{1}{|c|}{ Input data } & Value \\
\hline Production capacity of the installation, ha shift $^{-1}$ & 360 \\
\hline Amount of capsules for 1 ha, pcs. & 100 \\
\hline Duration of the installation operation, $\mathrm{h}$ & 8 \\
\hline Loading the capsules into the installation, $\mathrm{h}$ & every 2 \\
\hline Number of loadings per shift, pcs & 4 \\
\hline Diameter of the capsule, $\mathrm{mm}$ & 20 \\
\hline
\end{tabular}

The results of the scientific research were taken as a basis for the development of initial requirements for the experimental specimen of the installation for dispersal of mixed-age encapsulated trichograms.

Table 5

Technical characteristics of the installation and requirements for the trichogram capsules

\begin{tabular}{|c|c|}
\hline Technical characteristics of the installation & Value \\
\hline \multicolumn{2}{|c|}{ Overall dimensions of the installation } \\
\hline Length, mm & 1200 \\
\hline Width, mm & 900 \\
\hline Height, mm & 800 \\
\hline Mass of the installation, $\mathrm{kg}$ & 150 \\
\hline The production capacity, ha a shift & 360 \\
\hline Volume of the receiver, $\mathrm{dm}^{3}$ & 5 \\
\hline Operating air pressure in the receiver, $10^{5} \mathrm{~Pa}$ (bar) & $4 \ldots 6$ \\
\hline Number of the pneumatic guns, pcs. & 5 \\
\hline Inclination angle of the barrels, degrees & 45 \\
\hline The internal diameter of the barrel, $\mathrm{mm}$ & 21 \\
\hline Amount of capsules per hectare, pcs. & 100 \\
\hline Maximum distance of the flight of the capsule, $\mathrm{m}$ & 35 \\
\hline Distance between the capsules after dispersal, $\mathrm{m}$ & 10 \\
\hline Deviation of the path of the flight of the capsule, $m$ & 1 \\
\hline Impact time of air pressure upon the capsule, $\mathrm{s}$ & 0.5 \\
\hline Capacity of the hopper for capsules, $\mathrm{dm}^{3}$ & 4 \\
\hline Electric voltage, $\mathrm{V}$ & 12 \\
\hline \multicolumn{2}{|c|}{ Technical requirements for the trichogram capsules } \\
\hline Internal volume of the capsule, $\mathrm{cm}^{3}$, not less than & 1.5 \\
\hline Diameter of the capsule, mm, not more & 20 \\
\hline Thickness of the capsule wall, mm, not more than & 3 \\
\hline Material of the capsule & compressed paper waste \\
\hline
\end{tabular}


Alongside with the ballistic tests, the impact of the kinetic energy of the shot upon the quality indicators of the trichograms, located in the capsules, was determined. Particularly determined was the dependence of the emergence of the trichogram imago upon the pressure of the air supplied in the pneumatic gun. The shots were made, changing the air pressure from 8 to 2 bar. It was stated experimentally that at the air pressure of 8 atm, the imago output was 88-89\%, and at shots with a pressure of 3-4 bar, the imago output was $95-96 \%$, that is, there was almost no negative effect observed of the kinetic energy of the shot upon the trichogram. The results of these tests are presented in Fig. 4, 5 and 6.

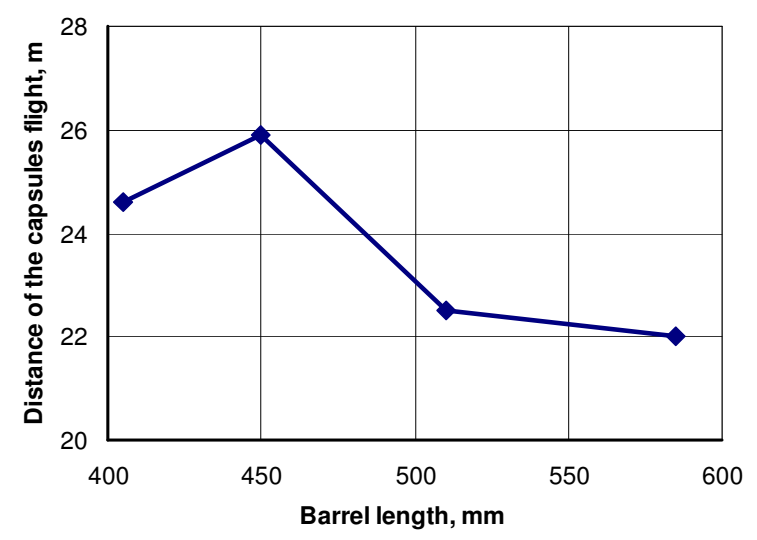

Fig. 4. Dependence of distance of flight of capsules upon length of barrel

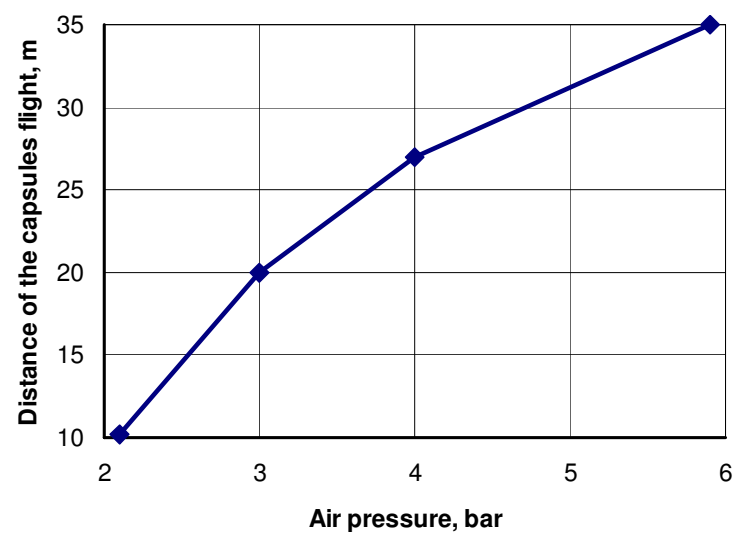

Fig. 5. Dependence of distance of flight of capsules upon air pressure

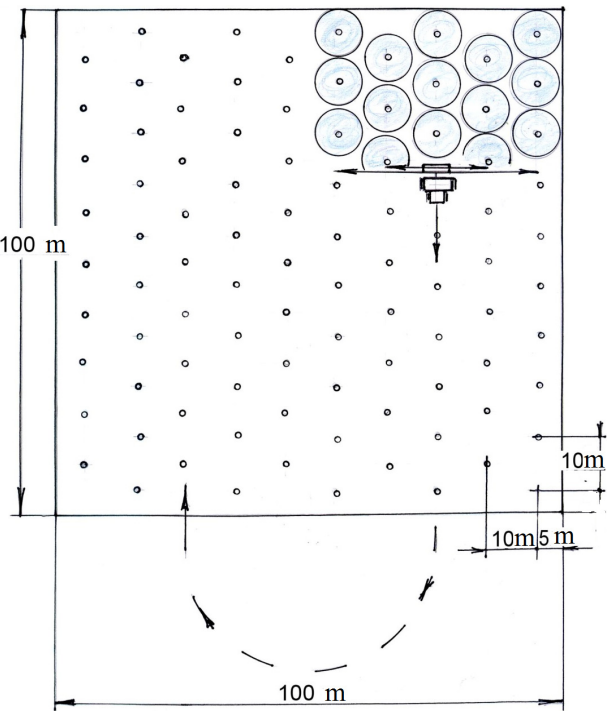

Fig. 7. Dispersal scheme of encapsulated trichograms

When choosing a scheme of the dispersal of the encapsulated trichograms, it was taken into account that the radius of the efficient searching behaviour of the female trichogram is not more than 5 $\mathrm{m}$. Guided by this consideration, the capsules must be located at a distance of $10 \mathrm{~m}$ from each other, that is, 100 capsules must be placed on one hectare. Accordingly, in each of the 100 capsules there should be packaged one hundredth of the total number of trichograms to be dispersed per one hectare.

The installation will be able to scatter five trichogram capsules in one shot - two on each side of the conditional axis of the movement at a distance of 10 and 20 meters, and the fifth capsule will fall directly on the axis of the movement. It is intended to implement uniform dispersal of the capsules over the area of the agrobiocenosis in the process of successive passes of the installation on the field along the rows of the plants. The dispersal scheme of the encapsulated trichograms is shown in Fig. 7. According to this scheme, the first pass of the installation should be carried out at a distance of $25 \mathrm{~m}$ from the edge of the field, the second in the opposite direction after $50 \mathrm{~m}$. 
Thus, the conducted functional tests of the experimental specimen of the installation for dispersal of encapsulated trichograms of different ages proved the functional suitability and economic expediency of the proposed method of spreading trichogram capsules over the area of the agrobiocenosis. Besides, it was established that the $450 \mathrm{~mm}$ length of the barrel of the pneumatic gun is quite sufficient for the flight of capsules to the distance of 20-22 m; the working air pressure in the receiver can be reduced to 5 bar; and no negative effect of the kinetic energy of the shot upon the imago output from the capsules was observed.

\section{Conclusions}

1. A computational mathematical model has been constructed, describing the dispersal of trichograms by means of a pneumatic installation.

2. It was established experimentally that for a shot at a distance of $20-25 \mathrm{~m}$, an air pressure of 4-5 bar is sufficient, and at $10 \mathrm{~m}$, an air pressure of 2-3 bar is sufficient.

3. It was found that the reduction in the length of the barrel to $450 \mathrm{~mm}$ will increase the distance of the flight of the capsule; yet further reduction in the length of the barrel to $400 \mathrm{~mm}$ will decrease also the distance of the flight of the capsule.

4. Constructive and kinematic parameters of the installation for scattering (dispersal) the capsules with trichograms have been determined, which ensures high uniformity of dispersal of the trichograms across the surface of the field.

\section{References}

[1] Barwicki J., Gach S., Ivanovs S. Proper utilization of soil structure for crops today and conservation for future generations. Engineering for Rural Development, Proceedings, Vol. 11, 2012, pp.10-15;

[2] Ivanovs S., Panasyuk V., Bulgakov V., Dukulis I. Impact of forced air flow upon introducing pesticides under conditions of lateral wind. Research in Agricultural Engineering, Vol.64(4), 2018, pp.176-180;

[3] Sigsgaard L., Herz A., Korsgaard M. , Wührer B. Mass release of Trichogramma evanescens and T. cacoeciae can reduce damage by the apple codling moth Cydia pomonella in organic orchards under pheromone disruption . Insects, Vol. 8, Issue 2, 2017, Article number 41;

[4] Hegazi E., Khafagi W., Herz A., Konstantopoulou M., Hassan S., Agamy E., Atwa A., Shweil S. Dispersal and field progeny production of Trichogramma species released in an olive orchard in Egypt. Turkish Journal of Biology, Vol. 32, Issue 2, 2008, pp. 127-133;

[5] Kuske S., Widmer F., Edwards P.J., Turlings T.C.J., Babendreier D., Bigler F. Dispersal and persistence of mass released Trichogramma brassicae (Hymenoptera: Trichogrammatidae) in nontarget habitats. Biological Control, Vol. 27, Issue 2, 2003, pp. 181-193;

[6] Lenteren J.C. The state of commercial augmentative biological control: plenty of natural enemies, but a frustrating lack of uptake. BioControl, Vol. 57, No 1, 2012, pp. 1-20;

[7] Timms J.E., Oliver T.H., Straw N.A., Leather S.R. The effects of host plant on the coccinellid functional respons: Is the conifer specialist Aphidecta obliterata L.) (Coleoptera: Coccinellidae) better adapted to spruce than the generalist Adalia bipunctata (L.), Biological Control, 47 (3), 2008, pp. 273-28;

[8] Bespalov I., Hodorchuk V. Fundamentals of engineering design of technological complexes for industrial production of entomophages. Materials of the International Scientific Conference "Plant Protection in Traditional and Ecological Agriculture". Institute of Genetics, Physiology and Plant Protection, Chisinau, 2018, pp.163-167;

[9] Lenteren J.C. The state of commercial augmentative biological control: plenty of natural enemies, but a frustrating lack of uptake. Biological Control, Vol. 57, No 1, 2012, pp. 1-20;

[10] Krutyakova V. Effective Technological Equipment for Mass Production of Entomophagous Insects and Mites Used for Biological Control. Journal of Agricultural Science and Technology, No 7, 2017, pp. 179-186;

[11] Krutyakova V. Effective Technological Equipment for Mass Production of Entomophagous Insects and Mites Used for Biological Control. Journal of Agricultural Science and Technology, No 7, 2017, pp. 179-186; 
[12] Nitharwal M., Kumawat K.C., Choudhary M., Jat R.G. Influence of biorational and conventional insecticides on the population of chrysoperla carnea (steph.) In green gram, vigna radiata (linn.) In semi-arid conditions. Biopesticides International, Vol. 9, Issue 1, 2013, pp. 83-87;

[13] A.I. Krylova, E.A. Antipova, D.V. Perevozkin. The derivation of the Saint-Venant equations. Bull.Nov.Comp.Center, Num.Model.in Atmosph.,etc., 16, 2017, pp. 21-35;

[14] Dreizler R.M., Ludde C.S. Theoretical Mechanics. Springer, Berlin. 2010. 